\title{
Using Human Universals to Teach Multicultural Perspectives
}

\author{
Elizabeth Stork \\ Robert Morris University \\ USA
}

Teaching college students about multicultural perspectives is now ubiquitous in

college learning environments, especially in the humanities and social sciences.

Methods employed, however, for bringing about the goals of social justice and

commercial opportunity are somewhat superficial for internalizing and

influencing long-term behaviors. The effects are more accessible when starting

from the point of universal human fears and needs and then examining the

behaviors and rationales for behaviors dissimilar peoples use to allay those

fears and meet their needs. Learning outcomes that demonstrate an

understanding of how universal fears and needs influence behaviors of human

beings may be more likely to promote justice and opportunity in people's daily

work and lives and likely to be more enduring.

Strategies for Learning about Diversity

Enhancing Diversity Content for Learning about Universal Human Needs

Conclusion: What Can Be Gained

Note

References

The primary goal of college multicultural perspectives courses is to impel students to be aware of the attitudes and beliefs they have about people that are different from them and to practice sensitivity in dealing with dissimilitude. In many college courses containing multicultural content, texts, films, news, and anecdotes are used to convey perceptions various people experience as subjects or objects of ignorance, misunderstanding, or prejudice. Then suggestions for practice and opportunities to empathize with the misunderstood (or ignored) are offered. Finally, learners are assessed as to amount of developed awareness and new knowledge. It is hoped that education about "them," compared to "us," improves our interactions, perceptions, and attitudes about the rights and values of different people. Thus, students may carry on with their core courses or disciplines with a more open, less stereotyped vision of individual people they interact with every day or may expect to meet through the course of their lives. Such, at least, is my experienced interpretation of college courses in multicultural diversity. Multicultural diversity courses such as these

\section{Strategies for Learning about Diversity}

What is lost by the what-to-know/how-to-behave approach is the knowledge of common threads that underlie all human behavior and justify our natural, maybe normative, tendencies. Generally speaking, in the last century, 
authors in several disciplines have explained our uniquenesses and our differences on the one hand, and the chasms between individuals and groups caused by holding tight to what we know and expect of others on the other hand. Both thrusts add to the science of human behavior but distance us from an understanding about human nature in the main - what human beings desire and require. However, the inverse of this, or a focus on what is universal about the human condition, especially in relation to other human beings, is a compelling way to teach about multicultural perspectives. This has been addressed by some authors in corporate diversity training (e.g., Ofori-Dankwa \& Bonner, 1998). Students can and do arrive at an epiphany of their communal place in humanity that changes the way they think about "same" and "different," "us" and "them." This paper will demonstrate how the internalization of shared human needs and fears can lead to their rapid and appropriate application to daily interactions with others.

Theoretically speaking, a number of purposes could be invoked for teaching multicultural perspectives to college students, but all or most are geared toward changing attitudes (and ideally, behaviors) from those that are parochial (including racial, ethnic, class, age and gender prerogatives) to those that are inclusive. Typically, theoretical frameworks or approaches are centered around identities (e.g. Ashford \& Mael, 1989; Brewer, 2000; Jenkins, 2000; Tajfel; 1981; Tajfel \& Turner, 1986), attitude transformation (e.g. Ajzen, 2001; Chaiken, Eagly \& Wood, 1996; Eiser, 1994; Plous, 2003), intergroup conflict or membership (e.g. Bell, 1997; Castano, Sacchi, \& Gries, 2003; Linville, Fischer, \& Salovey, 1989), social judgment (e.g. Sherif and Hovland, 1961), and the like. These approaches are clearly bent on changing attitudes and then practicing new, internalized behaviors, but not explicitly about binding people together in spite of variations. The effect is often, as it was in my own student life, the insistence that one's own "cultural" attitudes are offensive, resulting in an unmindful defensiveness. With defensiveness easily can come a closing of the mind, not a basis for an interest and appreciation of the gifts and commonalities of fellow human beings. The approach offered in this paper is geared toward improving our ability to understand how the social world looks to each of us and how it looks to those we think are different from us - how human beings are and how our imperfect and limited knowledge encourages us to be unmindful of our methods and products of interaction. Only then, can we can alter our cultural beliefs and our methods of interaction. In teaching this complex subject matter, I seek to defuse the criticism of cultural mindsets we have all learned but did not necessarily create and open minds to a position less defensive and more welcoming of the idea that people are just trying to meet their own needs in the ways they learned.

\section{Enhancing Diversity Content for Learning about Universal Human Needs}

I teach two multicultural perspectives courses at both the undergraduate and graduate levels in an Organizational Studies and Leadership program at a 
small private university in a large, old "rust-belt" city. Students are, for the most part, first-generation college students, and non-traditional - that is, the undergraduates are older than traditional students (average age 34), and nearly all are employed. Most say they are getting college degrees or master's degrees to move up in their organizations or to finally complete a degree. The courses are delivered in a hybrid format - partially online, partially on-ground. Selected anonymous excerpts of written work from a few students from a sample of more than 100 students in both undergraduate and graduate courses are used as examples throughout this essay.

The framework used for both courses is Brown's $(1991,2004)$ human universals. Brown, an anthropologist, distilled hundreds of findings from documented studies on societies and people into five broad fears that loosely but extensively capture human experience (Buckingham, 2005). These universal fears and needs are the fear of death - the need for security and basic sustenance; the fear of chaos - the need for order and authority; the fear of strangers - the need for belonging and identification; the fear of the future - the need for a plan and clarity; and the fear of insignificance - the need for love and significance. Brown's (1991) work is used to teach students that the fears and desires of human beings are similar across cultures, and these fears and needs are an optimistic and satisfying way of reducing our ignorance and our misunderstanding of others. When we recognize certain human universals about fears and needs, we can accept and empathize with others' attempts to meet those needs, allay those fears, and look for patterns and means by which other people (and ourselves) allay theirs. We can gaze upon this sameness with less prejudice and hostility. For example, realizing that it is human nature to group together can reduce the sting of our desire to stick with our own - which is ultimately to belong. The degree to which we stick with our own varies with exposure to others and openness of mind. Knowing we fear strangers, then, can be a strong motivator for learning about why we fear strangers and making sense of related human behaviors. Not considering our natural human inclination to belong can result in students believing their desire to stick to their own is pathological because it is antithetical to the goal of multicultural inclusiveness, as is commonly inculcated in many diversity courses.

\section{Self-Construction}

In their first assignment in the course, students are invited to describe themselves culturally. They name as many identifiers as they can think of - oneor two-word nouns - and then construct their "profile" through these. For instance, a female student might be a daughter, mother, sister, wife, student, and employee. Students consider how they see themselves, how they project themselves, and then how they assume others see them. Immediately, and uniformly, they recognize differences in how they believe they appear to others compared to the identifiers they hold dear. A conspicuous example is their religious identity, especially when artifacts are not displayed on their person, 
home, or workspace. Many students in these classes who name their devout Christianity, for example, as a strong cultural distinction of theirs are mildly surprised to note that their religious identification is not obvious and central to another's perception of them. Another early assignment is to "profile" someone they know at work or in a social context, first according to what they see and interpret through the person's behaviors and self-presentation. Then they must interview the subject of their profile and learn how the individual identifies him/herself on our course-prescribed dimensions: primary (those present at birth or in our genes or by virtue of a permanent change such as skin color, height, intellectual aptitude, ethnic identification, physical ability or disability), secondary (those central to our presentation of ourselves and not present in our DNA including education, income, class, geographical location, weight, nationality), and tertiary, such as described by Hampden-Turner and Trompenaars (2000) and Hofstede (2001), like universalism vs. particularism, communitarian vs. individualism, and seeking to analyze vs. seeking to integrate. Salient features or descriptors that students choose and interviewees select to reveal vary, students note, and they subject these descriptors to a fairly superficial, but critical, scrutiny. Students become more conscious of how each of us views ourselves and how we believe we present ourselves, and they begin to understand that those images are not as easily interpreted, or more significantly, understood, as students thought they were. Who a person is appears less obvious and less generalizeable than they each had thought. They find their assumptions are built on stereotypes, appearances, and behaviors, but their person-subjects are seldom as they seem upon observation. A student says ${ }^{1}$ :

The thing that I found so interesting was that my assumptions were based on personality traits that I thought resembled certain cultures. It is very difficult to make cultural assumptions about someone that you don't know that well. When you do that you tend to be biased and stereotype people based on logics that can be so wrong. The second lesson that I learned is that if you take the time to understand someone's culture you are only equipping yourself with more knowledge and a better appreciation of others.

Students also question their ability to make judgments about people from mere observations. Pedagogically, this assignment enables the dismantling of just one set of assumptions - that people know who they themselves and their acquaintances "are." They most often do not know how socially constructed their identity classifications are, nor are they cognizant of their prescribed worldviews; most cultural awareness courses do not explore the origins of our own "knowing." That these understandings surprise them, graduate students and educated "people of the world," is a little disconcerting to many of them but changes their vocabulary, one of the first manifestations of new insights and knowledge.

Through discussions, readings, and journal reflections, students learn about how they perceive the world and how others may perceive the world 
differently. They consider that the root of our fascination - and by inversion our irritation -- about other people has everything to do with differences and preferences in perceiving the world and our place in it. Therefore, understanding world views, how people think about their place and significance in relation to others, is more conducive to understanding why we sometimes get it wrong, why we sometimes insult, misunderstand, and disregard others.

This theme requires consistent and regular revisiting in the course. As students become aware of their own identifiers, those they hope people see and those they think people see, and they check their perceptions about themselves and others against the perceptions of others, new, rich raw materials surface. They consider standard multicultural concepts such as privilege, stereotyping, bias, prejudice, attitudes, and behaviors through readings, in frank discussions in class and in online threaded discussions, a relatively safe space to experiment. They write about waking up the next day a completely different version of themselves in primary dimension terms (if Black yesterday, White today; if young yesterday, old today; if male yesterday, female today), in the same circumstances, and reflecting on their joys and fears, their wants and needs, and their relationships. Students engage in multiple readings and exercises to recognize their own realities as assumptions, no more truthful than anyone else's, but deeply steeped in, and reinforced by, cultures trying to keep their members safe, just like their own.

\section{Human Needs and Fears}

Brown's (1991) human universals include common human activities and beliefs such as toilet training of small children, the use of weapons, the practice of taking turns, joking, tickling, fear of snakes, and playing with toys. But relevant for the purposes of teaching about multicultural perspectives, the five fears are these: fear of death, fear of strangers, fear of the future, fear of chaos, and fear of insignificance. Each of these fears has an accompanying need (Buckingham, 2005): need for security, need to belong, need for a plan or clarity, need for authority or order, and need for respect or significance. Through discussions and writing assignments (very adaptable, incidentally, to online teaching) students organize their thoughts and expand their attitudes and beliefs about the values and behaviors associated with these fears and needs. They supplement these thoughts with a variety of ideas: the idea of status anxiety to reinforce the fear of insignificance (de Botton, 2004), the idea of the tribal mind to support the natural fear of strangers and how we categorize (Berreby, 2005), the idea of global cultural dimensions to explain preferences for managing our environment (Hampden-Turner \& Trompenaars, 2000; Hofstede, 2001). Students then create a theme that forces not the pointing out of differences that ought or must be celebrated but the sameness that is at the core of what humans share and require because the samenesses are inherently valuable to and insistent about the human narrative. A student wrote: 
I've been making mental notes on how to take what we've learned about diversity and how to practically and productively apply it in the workplace as well as in our personal relationships with others. As we've pulled the 3 primary themes (Universal Fears and Needs, Us vs. Them, and Preferences) together, I'm repeatedly seeing four simple concepts (i.e. tolerance, understanding, acceptance and respect) as related to my mindset towards diversity. That doesn't mean I turned a blind eye or looked negatively at diversity in others before I took this course. I think knowledge breeds awareness and awareness certainly subdues or eliminates any pre-conceived biases or stereotypical thought. The universal fears and needs provides a grounded perspective. Regardless of the things we cannot change (race, nationality, ethnicity, sex), we ALL share commonalities in basic fears (chaos, insignificance, future, death, strangers) and needs (order, love, a plan, security, to belong). These Fears and Needs facilitate an awareness, understanding and (at least) a tolerance within us for the differences we see in others because we know we share some commonalities even before meeting them.

Using Berreby (2005) to fixate briefly on the tribal mind permits students to recognize, for instance, that belonging and identifying with a group or culture are human things to do (de Botton, 2004; Buckingham, 2005) and should not be denigrated as egocentric and unjust in multicultural learning. If something is first noted as universal and natural, that thing is more easily discussed as particular and individual (Berreby, 2005). Once the negativity is put in relevant terms and dealt with as the desire to belong and fit, students can feel safe exploring other ideas. Many multicultural courses begin or end with a presumption that one's own quarter, especially if that (American) quarter is White, male and Protestant, is "wrong" and to some degree or another perpetuates injustice and blindness. History and sociology most blatantly, but many course subjects in many ways prove humans are more than capable of injustice, cruelty, and dangerous ignorance, whatever their starting point. Enabling students to think more broadly and openly about privilege, rights, values, justice and commonalities of human beings is likely to be more successful than starting from a corrupted, critical standpoint as is stated or implied in many multicultural texts and training materials. The human brain organizes people and things in such ways as to manage them; this is not a human fault, but a norming activity. Understanding one's organizing principles, then trusting these principles enough to rearrange them to accept new knowledge is the goal of learning. Knowing we strive to belong and feel safest with what we know and understand gives us the wherewithal to engage with new and strange people and things. Says another student:

We come up with different categories or distinctions for people (as other students have stated in the past) to organize the thoughts in our mind. To separate them from us is to make sense of the world around us. And it's how we deal with the differences that we have with other people. We categorize people in 
several different ways: by race, religion, age, ethnicity, and gender just to name a few. Human beings use signs to distinguish between "human kinds" as Berreby (2005) suggested in his book, Us and Them. When we meet new people we look for these signs to make a connection with that other person. It also makes us feel comfortable with the other person once we find that sign to connect us as one category. Berreby (2005) says that it's like "drawing imaginary circles" in our minds by asking questions, to connect us with that other person in one "human kind."

Status anxiety plays nicely into the idea of fear of insignificance and desire for significance that Brown (1991) advances. Students read and discuss the concept of status and the universal need to matter, be noticed, fit, have value in someone's eyes, be loved, and be respected as Alain de Botton (2004) asserts. De Botton discusses origins of status anxiety and ways people overcome their success or failure worries. People experience many occasions to fear and need throughout their lives, but both significance and the maintenance of significance occupy most of us much of the time. Thinking about how differently we demonstrate this fear and assuage is, in my opinion, a core human concern and at the heart of our human diversity.

\section{Preferences for Dealing with the World}

Hofstede (2001) describes and provides evidence for five dimensions on which people of nations and ethnic groups internalize cultural preferences for managing their environments. These dimensions are, loosely and briefly defined: power distance (perceived power inequalities between two people), uncertainty avoidance (tolerance for ambiguity), individualism vs. collectivism (primary concern for the individual vs. primary concern for the group), masculinity vs. femininity (competitive vs. relational), and long- vs. short-term orientation (consumption vs. frugality). The cultural baptisms we receive just by occupying geographical regions and histories together cause us to perceive time, distance, togetherness, interactions, emotions, and behaviors differently in ways that influence thinking and behavior. Students easily absorb these points of departure and preferences for dealing with the world around us, evolved through culture, that enable us to predict not only how individuals feel and act, but how organizations do as well. Hampden-Turner and Trompenaars (2000) have a similar position on culture but couch it in a more accessible manner for practical application to many organizational priorities. They compare culture-defining dimensions and how they are managed and reconciled to enable integration rather than polarization of practices and ideas. These dimensions are: universalism vs. particularism (seeks similarities vs. seeks the exception), individualism vs. communitarism (competition vs. cooperation), specificity vs. diffuseness (precise details - the trees - vs. patterns - the forest), achieved status vs. ascribed status (earned vs. inherited status), inner-directed vs. outerdirected (virtue resides in our consciousness vs. in our relationships), and sequential time vs. synchronous time (events happen in increments one after the 
other vs. events happen in circuitous evolutions). Both of these sets of ideas are collapsed into tertiary dimensions for learning purposes, yet Hampden-Turner and Trompenaars' dimensions (and book) are easier for students to grasp. This final section brings home the specific elements of diversity demonstrated by people students meet in the course of their work, here and abroad.

\section{Conclusion: What Can Be Gained}

Understanding what makes us different is more satisfactorily and deeply internalized when we focus on how differently people manage, approach, resolve, or integrate their similar needs and fears. We all want the same general things - to be secure, to feel significant, to live with order, to have a future, and to belong (Berreby, 2005; Buckingham, 2005; Brown, 1991; de Botton, 2004). How members of the human race go about attaining those things can be a fascinating and long-lasting discovery for students taking courses on diversity. This, done with a mind toward the primary theme of humanness and a core set of universal fears and needs, results in learners who have a profoundly new outlook about their fellow human beings. Enabling students to become aware of universal needs and fears that are common to human beings rather than starting from a critical stance that intimates offensive and defensive attitudes is more likely to result in students' actual enjoyment and keener understanding of a consequential topic they will always and increasingly be facing. Four students wrote:

As has been repeatedly pointed out in this class, even with our differences we are more alike than not. So, if we are all alike, we most certainly want to achieve something for ourselves to be distinguishable from the crowd. I find comfort in the universality of this theme. I have always believed this sentiment to be true but did not have the framework to express my beliefs. Now I do.

It is very difficult to keep an open mind sometimes. Most people I know, including myself, have this need to be right all the time, and it can be very difficult to be told that what you are thinking is wrong, no matter what the topic. Explaining our preferences is not the hard part, it is changing them. Even if I know in my brain that a belief is irrational, that does not necessarily stop me from acting on the belief. Changing an inappropriate belief can easily take a lifetime of learning, especially if an opportunity to promote change does not present itself.

Many times our perceptions how we perceive the world are changed by knowledge. The more you know about the "themes" of the world, the better your outlook on life will be.

We all have past experiences, parents, teachers, and others shaping our paradigm of the world around us. People perceived to have different status in society may see the world differently depending on their past 
experience, however it is not uncommon to see a paradigm shift once a person has been exposed to more education and information. For instance several weeks back Dr. Stork asked if people are equal and I said yes. Information was presented to me that I had not thought about and I quickly changed my mind. The more we learn the more our view on the world changes.

\section{Note}

1. Student writings are not edited in this article.

\section{References}

Abrams, L. S., \& Gibson, P. (2007). Reframing multicultural education: Teaching white privilege in the social work curriculum. Journal of Social Work Education, 43,147-160.

Adams, M., Griffin, P., \& Bell, L. (2007). Teaching for diversity and social justice (2nd ed.). New York: Routledge.

Ajzen, I. (2001). Nature and operation of attitudes. Annual Review of Psychology, $52,28-58$.

Ashford, B. E., \& Mael, F. (1989). Social identity theory and the organization. Academy of Management Review, 14, 20-39.

Bell, L. A. (1997). Theoretical foundations for social justice. In M. Adams, L.A. Bell \& P. Griffin (Eds.), Teaching for diversity and social justice: A sourcebook (pp. 3-15). New York: Routledge.

Berreby, D. (2005). Us and them: Understanding your tribal mind. New York: Little, Brown and Company.

Brewer, M. B. (2000). Reducing prejudice through cross-categorization: Effects of multiple social identities. In S. Oskamp (Ed.), Reducing prejudice and discrimination (pp. 165-183). Mahwah, NJ: Lawrence Erlbaum.

Brown, D. (1991). Human universals. New York: McGraw-Hill.

Brown, D. (2004). Human universals, human nature \& human culture. Daedalus, $133,47-55$.

Buckingham, M. (2005). The one thing you need to know. New York: Free Press.

Castano, E., Sacchi, S., \& Gries, P. H. (2003). The perception of the other in international relations: Evidence for the polarizing effect of entitativity. Political Psychology, 24, 449-468.

Chaiken, S., Eagly, A. H., \& Wood, W. (1996). Principles of persuasion. In E. T. Higgins \& A. W. Kruglanski (Eds.), Social psychology: Handbook of basic principles. (pp. 702-742). New York: Guilford Press.

De Botton, A. (2004). Status anxiety. New York: Pantheon Books. 
Eiser, J. R. (1994). A brief history of attitude research. In Attitudes, chaos and the connectionist mind (pp. 1-31). Oxford, UK: Basil Blackwell.

Hampden-Turner, C. M., \& Trompenaars, F. (2000). Building cross-cultural competence. New Haven: Yale University Press.

Hofstede, G. (2001). Culture's consequences. Thousand Oaks, CA: Sage Publications.

Jenkins, R. (2000). Categorization: Identity, social process and epistemology. Current Sociology, 48, 7-25.

Linville, P. W., Fischer, G. W., \& Salovey, P. (1989). Perceived distributions of characteristics of ingroup and outgroup members: Empirical evidence and a computer simulation. Journal of Personality and Social Psychology, 57, $165-188$.

Ofori-Dankwa, J., \& Bonner, R. (1998). A new look at corporate diversity training and management: From affirming diversity to affirming diversimilarity. Multicultural Review, 7, 40-43.

Plous, S. (2003). Understanding prejudice and discrimination. New York: McGraw-Hill.

Sherif, M., \& Hovland, C.I. (1961). Social judgment: Assimilation and contrast effects in communication and attitude change. New Haven, CT: Yale University Press.

Tajfel, H. (1981). Human groups and social categories: Studies in social psychology. Cambridge: Cambridge University Press.

Tajfel, H., \& Turner, J.C. (1986). The social identity theory of intergroup behavior. In S. Worchel \& W. Austin (Eds.), The psychology of intergroup relations (2nd ed., pp. 7-24). Chicago: Nelson-Hall. 